\title{
Avaliação da qualidade microbiológica de polpas de cupuaçu (Theobroma grandiflorum schum) comercializadas no município de Guaraí/TO
}

O cupuaçuzeiro (Theobroma grandiflorum Schum) trata-se de uma espécie vegetal pertencente à família das Sterculiaceas, de origem amazônica, frequentemente encontrada ao Sul e Sudeste da Amazônia Oriental e ao Noroeste do Estado do Maranhão. A polpa do cupuaçu é intensamente consumida pela população brasileira para a produção de alimentos. A extração da polpa de forma artesanal geralmente ocorre sem nenhum tipo de tratamento específico, com o auxílio de tesouras. Esta prática de despolpamento aumentam as possibilidades de contaminação por microrganismos deteriorantes do alimento e/ou por patógenos humanos que podem causar inúmeras doenças de origem alimentar (DTAs). O objetivo do presente trabalho é expressar os resultados da análise de Coliformes, termotolerantes e de Escherichia coli em polpas de cupuaçu comercializadas por estabelecimentos no município de Guaraí/To, a partir da metodologia do Número Mais Provável (NMP) em uma série de 10 tubos, considerando-se que não existem trabalhos com esta finalidade realizados no Município. Em geral, os resultados encontrados no trabalho indicam que a maioria dos lotes coletados para a realização da pesquisa não apresentaram contaminação por Coliformes, presença de Termotolerantes e Escherichia coli, e que somente 1 lote apresentou resultados fora daqueles estabelecidos pela RDC $n^{\circ} 12$, de 02 de Janeiro de 2001 , que provavelmente ocorreu pelo rompimento da embalagem. Desta forma, conclui-se que se faz necessário a realização de fiscalizações nos ambientes comerciais para atestar as condições de armazenamento e manuseio destas polpas no município, assim como a conscientização dos riscos de contaminação do alimento por práticas inadequadas realizadas nestes estabelecimentos.

\section{Evaluation of the microbiological quality of cupuaçu pulps (Theobroma grandiflorum schum) marketed in the municipality of Guaraí/TO}

\begin{abstract}
The cupuaçuzeiro (Theobroma grandiflorum Schum) is a plant species belonging to the family of Sterculiaceas, of Amazonian origin, often found in the South and Southeast of the Eastern Amazon and in the Northwest of the State of Maranhão. The pulp of cupuaçu is intensely consumed by the Brazilian population for the production of food. Extraction of the pulp in a handcrafted way usually occurs without any specific treatment, with the aid of scissors. This pulping practice increases the chances of contamination by foodborne microorganisms and / or human pathogens that can cause numerous foodborne diseases (DTAs). The objective of the present work is to express the results of the analysis of coliforms, thermotolerant and Escherichia coli in cupuaçu pulps marketed by establishments in the municipality of Guarai / TO, using the Most Probable Number (NMP) methodology in a series of 10 tubes, considering that there are no works with this purpose carried out in the Municipality. In general, the results found in the study indicate that most of the lots collected for the research did not present contamination by Coliforms, presence of Thermotolerantes and Escherichia coli, and that only 1 batch presented results outside those established by RDC No. 12 of 2 January 2001 , which was probably due to the breaking of the packaging. In this way, it is concluded that it is necessary to carry out inspections in commercial environments to attest to the conditions of storage and handling of these pulps in the municipality, as well as the awareness of the risks of food contamination due to inadequate practices performed in these establishments.
\end{abstract}

Keywords: Total coliforms; Fecal coliforms; Thermotolerant; Escherichia coli.

Topic: Microbiologia

Reviewed anonymously in the process of blind peer.

Wceilayla Marthiely Souza dos Santos

Faculdade Guaraí, Brasil

http://lattes.cnpq.br/1763975983187996

marthielylayla@gmail.com

Tainara Siqueira Cardoso

Faculdade Guaraí, Brasil

http://lattes.cnpq.br/1422599223362057

tainarasiqueira12@gmail.com

Josenilda Guimarães Lopes

Universidade Federal do Tocantins, Brasil

http://lattes.cnpq.br/8950407070961798

Iguimaraes@mail.uft.edu.br
Received: 14/12/2017

Approved: 26/12/2017

Simone Pôssas Andrade

Universidade Federal do Tocantins, Brasil

http://lattes.cnpq.br/0552128506796918

simone.andrade@iescfag.edu.br

Ana Paula Martins Guimarães

Universidade Federal do Tocantins, Brasil

http://lattes.cnpq.br/9694032726460437

biologa.apmg@gmail.com
Referencing this:

SANTOS, W. M. S.; CARDOSO, T. S.; LOPES, J. G.; ANDRADE, S. P.; GUIMARÃES, A. P. M.. Avaliação da qualidade microbiológica de polpas de cupuaçu (Theobroma grandiflorum schum) comercializadas no município de Guaraí/TO. Scire Salutis, v.7, n.2, p.20-31, 2017. DOI: http://doi.org/10.6008/SPC2236-9600.2017.001.0003 


\section{INTRODUÇÃO}

Existe uma grande variedade de vegetais nativos do Brasil distribuídos em seus diferentes biomas e que fornecem frutos de importância nutricional e econômica para a população, que não são encontrados em territórios exteriores ao brasileiro. Um exemplo destes vegetais é a espécie Theobroma grandiflorum, conhecida popularmente por cupuaçu (RAMOS, 2004).

O cupuaçuzeiro é uma espécie vegetal pertencente à família das Sterculiaceas, de origem amazônica, frequentemente encontrada ao Sul e Sudeste da Amazônia Oriental e ao Noroeste do Estado do Maranhão. Sua distribuição se apresenta ampla ao longo da bacia Amazônica, sendo ocasionalmente encontrada em outros estados do território brasileiro e até mesmo em alguns outros países fronteiriços ao Brasil (VENTURIERE et al., 1988).

Os frutos do cupuaçu têm um rendimento de polpa que modifica de acordo com a dimensão, a origem, o tempo de safra e o processo de extração utilizado. Os frutos carregam em torno de $1,275 \mathrm{~kg}$, significando que, deste peso total, pode-se obter em torno de $38,5 \%$ de polpa processada, sendo considerada uma ótima fonte de matéria-prima para a produção de uma variedade de alimentos derivados de sua polpa.

Outra vantagem do cupuaçu é que essa fruta tem por opção de ser produzido no período da safra, podendo ser armazenado e processado conforme as necessidades de utilização do consumidor, podendo ser comercializado em várias conformações, como por exemplo: em forma de geleias, ou em vários tipos de doces, sucos e até mesmo a venda do produto in natura (MOREIRA et al., 2011).

Por se tratar de frutos perecíveis que se autodeterioram em poucos dias, pois sofrem influência de microrganismos endógenos do próprio fruto e em alguns casos exógenos a eles, apresentam sua negociação in natura dificultada, sendo necessário que o seu armazenamento seja realizado por meio de criopreservação para evitar grandes perdas de produção (FREIRE et al., 2009).

A obtenção da polpa ocorre por meio de despolpamento manual de forma artesanal ou mecânica utilizando-se de maquinários apropriados para este fim. Na maioria das vezes, o despolpamento é realizado de forma artesanal com o auxílio de tesouras ou outros materiais cortantes produzidos de aço inoxidável ou outros objetos que possibilitam a extração da polpa, sendo que esta metodologia é frequentemente utilizada e viabiliza a contaminação por deteriorantes e em alguns casos, até mesmo por patógenos humanos (FREIRE et al., 2009).

A contaminação de determinados alimentos geralmente estão relacionadas ao grupo de microrganismos indicadores, pertencentes à microbiota entérica de animais de sangue quente e até mesmo do ser humano que, quando presentes em um dado alimento, podem prover dados sobre episódios de contaminação de origem fecal, possibilitando a suspeita da presença de micróbios deteriorantes do alimento ou até mesmo patogênicos, além de simbolizar uma péssima qualidade sanitária no processamento do alimento infectado (DANTAS et al., 2012).

Estes alimentos infectados, usualmente, têm apresentação, aroma e paladar normais, e a sociedade é insuficientemente elucidada sobre as ameaças que estes alimentos contaminados podem provocar 
(MARCHI et al., 2011), as quais instituem um dos impasses da atualidade mundial mais recorrente na saúde pública, sendo provocadas por agentes etiológicos, principalmente microrganismos, que adentram no organismo humano por intermédio do consumo de água e alimentos contaminados (WELKER et al., 2009).

A circunstância causadora da maioria dos surtos alimentícios é advinda da relação entre alimentos já contaminados que são expostos a armazenamento impróprio e que possibilita a propagação dos microrganismos, elevando a probabilidade de DTAs (MARCHI et al., 2011). Porém a investigação laboratorial permite obter conclusões sobre os agentes etiológicos, o propagador, local de incidência e outras particularidades.

Os agentes patogênicos que estão frequentemente envolvidos nas Doenças Transmitidas por Alimentos (DTAs) nos últimos anos são: Campylobacter sp, Salmonella sp e Escherichia coli (E. coli), sendo que a maioria dos casos informados de DTAs humanas foram causadas principalmente por Campylobacter jejuni e Escherichia coli (FEITOSA et al., 1997; BENEVIDES et al., 2008).

Para evitar as DTAs e garantir a plena qualidade microbiológica e físico-química das polpas de frutas vendidas, carece exercer a resolução $\operatorname{RDC} n^{\circ} 12$, de 02 de janeiro de 2001, a qual dispõe sobre critérios de Boas Práticas de Produção de Alimentos e pontos de controle da qualidade microbiológica dos produtos alimentícios (BRASIL, 2001), tendo como complemento a Instrução Normativa n01, de 07 de janeiro de 2000, a qual relata as formas de identificação e qualidade destes produtos (BRASIL, 2000).

Diante das informações citadas acima, o presente trabalho tem por objetivo expressar os resultados encontrados nas análises de Coliformes totais, termotolerantes e Escherichia coli em polpas de cupuaçu artesanais comercializados no município de Guaraí, estado do Tocantins, a fim de atestar a qualidade e a viabilidade de consumo destas polpas neste município.

\section{MATERIAIS E MÉTODO}

\section{Descrição da área de coleta}

As amostras de polpa de cupuaçu foram transladadas da feira municipal de Guaraí/TO. O estado do Tocantins, o mais novo da Federação, com apenas 27 anos de existência em franco crescimento se evidencia como uma das economias mais prósperas da região norte do Brasil. A presente pesquisa desenvolvida no município de Guaraí, pertencente ao estado do Tocantins, conforme se nota na figura 1, no qual possui uma extensão territorial de $2.268 \mathrm{~km}^{2}$ e está situado na Mesorregião Ocidental do Tocantins e Microrregião de Miracema do Tocantins, sede da 6a Região Administrativa do Estado, distante $173 \mathrm{~km}$ da capital do estado, Palmas (IBGE, 2016). 


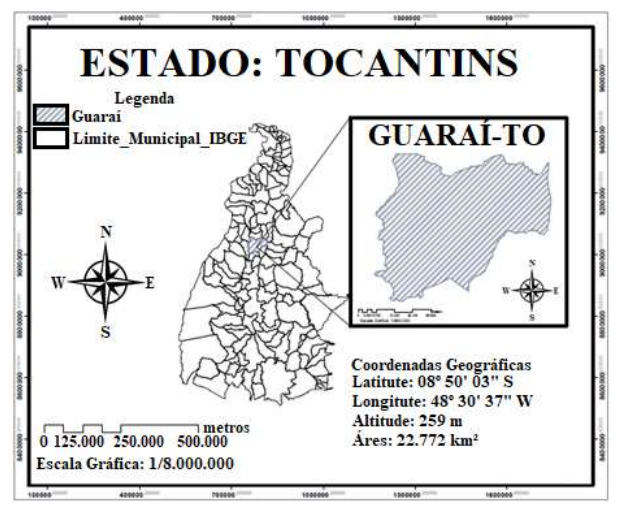

Figura 1: Estado do Tocantins, com destaque para o Município de Guaraí, onde foram efetivadas as coletas para o estudo com polpas de cupuaçu vendidas no Município. Fonte: Roberto et al., (2017).

O município possui uma população estimada de 25.399 habitantes. Guaraí está localizado entre as coordenadas $08^{\circ} 50^{\prime} 03^{\prime \prime}$ S e $48^{\circ} 30^{\prime} 37^{\prime \prime}$ O (IBGE, 2016). O clima da região, segundo a classificação de Koeppen (1948), é do tipo Aw com duas estações bem definidas (um período chuvoso e outro seco). O município é considerado como um importante centro comercial da região. Além disso, sua economia baseia-se fortemente na agricultura e pecuária (IBGE, 2016).

\section{Procedimentos de coleta das polpas}

Foram coletadas 15 amostras (15 lotes) de polpa de cupuaçu, produzidas artesanalmente e comercializados no município de Guaraí, interior do estado do Tocantins, de acordo com a figura 2A. Todos os procedimentos de coleta, transporte e armazenamento foram executados de acordo com recomendações do Guia de Coleta e Preservação de Amostras formulado pela Cetesb (2002) e as recomendações de Silva et al. (2007) para amostras congeladas.

As polpas foram adquiridas de forma direta, compradas de 3 comerciantes locais, seguindo as recomendações de Silva et al. (2001) que consiste em averiguar se a embalagem original do produto não estava rompida ou rasgada antes da aquisição da polpa. Após as coletas, cada amostra foi armazenada em caixas isotérmicas até o seu devido processamento em laboratório específico para a realização das análises (CETESB, 2002; SILVA et al., 2007).

\section{Processamento das amostras}

No Laboratório de Análises Clínicas (MULT III) do Instituto Educacional Santa Catarina/Faculdade Guaraí (IESC/FAG), os lotes das polpas de cupuaçu foram processados e analisados através de testes microbiológico de Coliformes totais, fecais, termotolerantes e de Escherichia coli para atestar a qualidade microbiológica e a viabilidade de consumo destas polpas.

\section{Análise de Coliformes totais, fecais e termotolerantes}

Para a realização dos testes microbiológicos foi utilizada a metodologia do Número Mais Provável (MNP) com tubos múltiplos, seguindo o protocolo e as recomendações citadas por Vanderzant et al. (1992) 
e por Silva et al. (2007), baseada no método de fermentação de diferente açúcares em uma série de 3 tubos para cada diluição, que determina o Número Mais Provável (NMP) de coliformes em $25 \mathrm{~g}$ de polpa. 0 processamento das amostras foi executado de forma asséptica, dentro de uma capela de fluxo laminar prédesinfeccionada com álcool 70\%, em seguida com um banho de iluminação UV por 15 minutos a fim de reduzir os riscos de contaminação das amostras.

Ao iniciar o processamento dos lotes de polpa de cupuaçu, extraiu-se de cada amostra de $25 \mathrm{~g}$ de polpa, como se observa na figura 2B, em triplicata e de forma asséptica utilizando-se de faca inoxidável esterilizada em aparelho de autoclave a $121^{\circ} \mathrm{C}$ por $15 \mathrm{~min}$. Em seguida, os inóculos foram transferidos para frascos do tipo Erlemyer contendo $225 \mathrm{ml}$ de solução salina estéril a 0,9\%, suplementada com peptona de carne a $0,1 \%$, de acordo com o ilustrado na figura 2C. Estas amostras, então, passaram por homogeneização manual, com agitação do frasco em movimentos circulares por 5 min (AMORIM et al., 2010).

Após a homogeneização, as amostras passaram por diluições seriadas em tubos de ensaio contendo solução salina a 0,9\%, suplementada com peptona de carne (0,1\%). Em cada tubo de ensaio continha $9 \mathrm{ml}$ de solução salina, como demonstrado na figura 2D. De cada amostra foram retiradas uma alíquota de $1 \mathrm{ml}$ com o auxílio de uma pipeta calibrada e inoculadas nos tubos de ensaio com as consecutivas diluições: $10^{-1}, 10^{-2}$ e $10^{-3}$. De acordo com Alves et al. (2002), as diluições são realizadas para posteriormente iniciar a realização do teste do NMP de Coliformes totais, fecais, termotolerantes e de Escherichia coli, consistindo de uma etapa presuntiva e outra confirmativa.

A primeira etapa diz respeito aos testes para identificação da presença de Coliformes totais em cada lote de polpa, sendo que, na etapa presuntiva, foram extraídos de cada diluição $1 \mathrm{ml}$, que foram inoculadas em tubos de ensaio contendo em seu interior tubos de Durham invertidos e $9 \mathrm{ml}$ de Caldo Lauril Sulfato Triptose (LST), numa série de 10 tubos, sendo 3 tubos para cada diluição e um tubo sem o inóculo para a leitura dos resultados. Estes tubos foram incubados a $36^{\circ} \mathrm{C}$ em estufa bacteriológica de 24 a $48 \mathrm{~h}$. Ao final do período de incubação, foram julgados positivos e conduzidos para o teste confirmativo de Coliformes totais os tubos que apresentaram crescimento com a turvação do meio de cultura e gás no interior dos tubos de Durham, ilustrado na figura 3A (SANTOS et al., 2008).

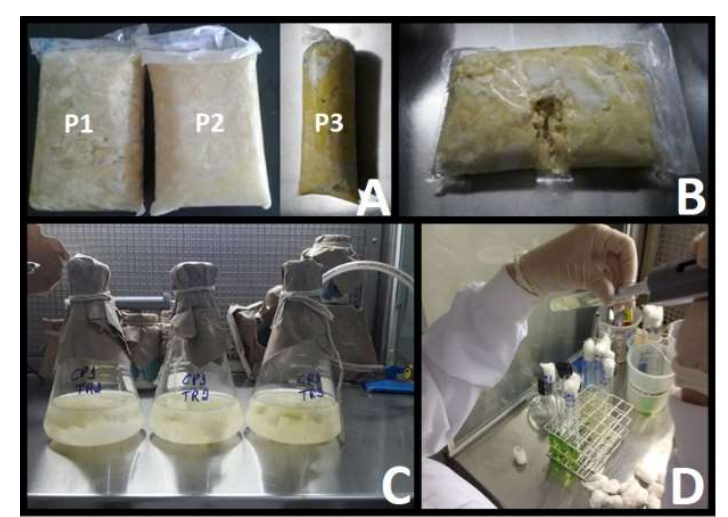

Figura 2: Processamento das amostras de polpa de Theobroma grandiflorum Schum. A) amostras de polpa dos 3 comerciantes de Guaraí; B) retirada da triplicata para a realização do processamento; C) triplicata com $25 \mathrm{~g}$ da polpa de cupu em $225 \mathrm{ml}$ de solução salina suplementada com peptona de carne; e D) retirada de $1 \mathrm{ml}$ da amostra para a realização das diluições seriadas em $9 \mathrm{ml}$ de solução salina suplementada com peptona de carne em $10^{-1}, 10^{-2}$ e $10^{-3}$. 
Para a real conclusão da presença de Coliformes totais, foram levados em consideração as seguintes informações sobre este grupo de microrganismos: classificados como bacilos gram-negativos que não formam esporos, podem ser aeróbicos, anaeróbicos ou facultativos que fermentam a lactose e produzem ácidos ou gás em uma temperatura média de $35^{\circ} \mathrm{C}$ (APHA, 2001). Com estas características, estão incluídos especialmente os gêneros Escherichia, Enterobacter, Klebsiella e Citrobacter (SILVA et al., 2007).

Os tubos positivos em caldo LST foram então encaminhados para o teste confirmativo em Caldo Verde Brilhante Bile a 2\% (VBB) em tubos de ensaio contendo tubos de Durham invertidos. Posteriormente, foi retirada uma alçada do Caldo LST positivo e inoculados no Caldo VBB, e em seguida incubados em estufa bacteriológica a $36^{\circ} \mathrm{C}$ por um período compreendido de 24 a $48 \mathrm{~h}$. Após o período de incubação, os tubos que exibiram turvação no meio de cultura e gás no interior do tubo de Durham, conforme se nota na figura 3B, foram considerados positivos e confirmam a presença de contaminação por coliformes totais na amostra pesquisada, comparando estes resultados com a tabela do Número Mais Provável (NMP) indicada pela Standard Methods (APHA, 1997; APHA, 2001) para a quantificação de contaminação por Coliformes totais em cada grama de cada polpa, de acordo com o recomendado pela American Public Health Association descritos por Vanderzant et al. (1992) e por Silva et al. (2007).

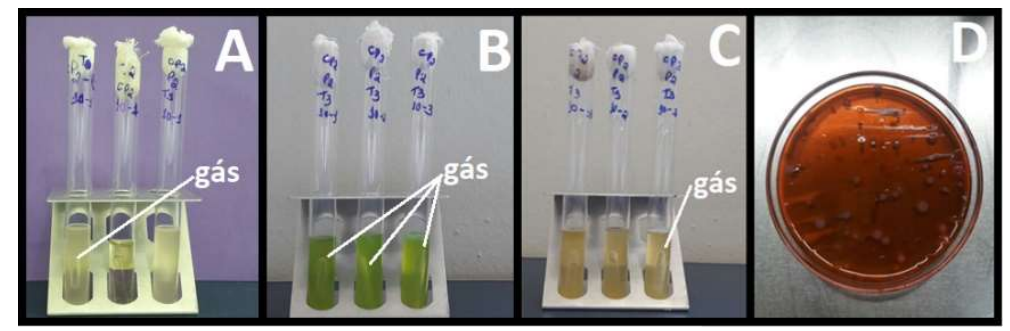

Figura 3: Expressão dos resultados nos diferentes meios de cultura. A) amostra positiva em caldo LST; B) amostras positivas em caldo VBB; C) amostras positivas em caldo Escherichia coli; D) amostras negativas em ágar BEM para a presença de Escherichia coli.

Dos tubos positivos em Caldo LST, também foi retirada uma alçada e inoculada em tubos de ensaio contendo tubos de Durham invertidos e Caldo Escherichia coli (EC). Estes tubos foram encaminhados para a incubação em aparelho de banho-maria a $45,5^{\circ} \mathrm{C}$ por um período compreendido entre 24 a $48 \mathrm{~h}$ para a determinação de Coliformes fecais. No decorrer deste período de incubação, realizou-se a leitura dos resultados, em que foram considerados positivos somente os tubos que apresentaram turvação do meio de cultura e exibição de gás no interior do tubo de Durham, ilustrado pela figura 3C. A partir destes resultados, possibilitou-se então a quantificação por meio do NMP para chegar a quantidade de contaminação de Coliformes fecais por grama da polpa de cupuaçu (VANDERZANT et al., 1992). Os tubos positivos em Caldo EC foram então dirigidos para a etapa de confirmação da presença de Escherichia coli através do isolamento de colônias típicas e testes bioquímicos.

Dos tubos positivos em Caldo EC retirou-se uma alçada e inoculou-se em placas de petri contendo meio de cultura Agar Eosina Azul de Metileno (EMB). Estas placas foram incubadas em estufa bacteriológica em temperatura de $36^{\circ} \mathrm{C}$ por $24 \mathrm{~h}$. Ao decorrer o período de incubação observou-se o crescimento de colônias 
típicas de Escherichia coli (colônias nucleadas com o centro negro e brilho verde metálico). Estas colônias então foram isoladas e encaminhadas para o teste bioquímico IMViC (indol, vermelho de metila/VogesProskauer e citrato), de acordo com a técnica descrita por Vanderzant et al. (1992) e Silva et al. (2007).

\section{RESULTADOS E DISCUSSÃO}

Foram analisados 15 lotes de polpa de cupuaçu processadas de forma artesanal e adquiridas de 3 comerciantes diferentes no Município de Guaraí, estado do Tocantins, ou seja, 5 lotes de cada comerciante, para avaliar a qualidade microbiológica destas polpas. De forma geral, as amostras apresentaram-se com ótima qualidade microbiológica e, portanto, indicada para o consumo sem o risco de transmissão de doenças por bactérias de fezes de animais de sangue quente ou ser humano, pois nos diferentes meios de cultura, apresentaram resultados dentro daqueles estabelecidos pela resolução RDC $\mathrm{n}^{\circ} 12$ de 02 de Janeiro de 2001, que avalia a qualidade de alimentos no Brasil.

As amostras de polpas de cupuaçu do produtor 1 apresentou total ausência tanto de Coliformes totais como de coliformes fecais e de Escherichia coli, pois todas as amostras apresentaram resultados negativos de turvação dos diferentes meios (L.S.T, V.B.B e E.C) cultura e produção de gás no interior do tubo de Durham. Mesmo apresentando resultados negativos, estas amostras foram inoculadas em meio ágar Eosina Azul de metileno (EMB) e incubadas a $36^{\circ} \mathrm{C}$ por $24 \mathrm{~h}$, que também apresentaram resultados negativos para o crescimento de colônias típicas de Escherichia coli.

Estas amostras também passaram pelo teste bioquímico de confirmação da para a presença de Escherichia coli IMViC (indol, vermelho de metila/Voges-Proskauer e citrato) e em nenhum dos 4 testes bioquímicos em que as amostras foram submetidas apresentaram resultados positivos para Escherichia coli, apresentando uma quantidade de Número Mais Provável de 0,0NMP/g de polpa de cupuaçu em todos os 5 lotes analisados do produtor 1 , e em nenhum dos lotes ouve crescimento com a turvação do meio de cultura, estando de acordo com o que é preconizado pela Agência Nacional de Vigilância Sanitária (ANVISA), através da RDC № 12 de 02/01/2001, portanto, liberadas para consumo.

Estes resultados estão de acordo com aqueles encontrados Santos et al. (2008) em seu trabalho intitulado 'Avaliação microbiológica de polpas de frutas congeladas', pesquisando em Palmas/TO, realizadas em diferentes tipos de polpas, inclusive de cupuaçu e, utilizando-se da metodologia de Número Mais Provável, que também obtiveram resultados semelhantes aos encontrados no presente trabalho com 0,0NMP/g de polpa.

Freire et al. (2009) também encontraram resultados que reafirmam aqueles encontrados na pesquisa. Em seu trabalho intitulado 'Caracterização físico-química, microbiológica e sensorial de polpa de cupuaçu congelada (Theobroma grandiflorum Schum)', Freire et al. (2009), que trabalharam com testes de detecção de coliformes a 30 e $45^{\circ} \mathrm{C}$, obtiveram resultados inferiores a 0,3NMP/g em polpas comercializadas por 3 produtores de São Paulo. Portanto, os resultados obtidos respeitaram a legislação, ao qual define que 
para cada $25 \mathrm{~g}$ de polpa é necessário encontrar total ausência de Salmonella e 1,0NMP/g de Coliformes totais e termotolerantes (BRASIL, 2001).

Tabela 1: Resultado de presença e ausência de Coliformes e termotolerante em amostras de polpa de cupuaçu artesanal comercializadas no Município de Guaraí/TO pelo produtor 1 e que foram inoculadas nos diferentes meios de cultura.

\begin{tabular}{|c|c|c|c|c|c|c|c|c|c|c|}
\hline \multicolumn{11}{|c|}{ PRESENÇA E AUSÊNCIA DE COLIFORMES E TERMOTOLERANTES } \\
\hline & & \multicolumn{3}{|c|}{ L.S.T. } & \multicolumn{3}{|c|}{ V.B.B } & \multicolumn{2}{|c|}{ E.C. } & \multirow[b]{2}{*}{$10^{-3}$} \\
\hline LT & D $T$ & $10^{-1}$ & $10^{-2}$ & $10^{-3}$ & $10^{-1}$ & $10^{-2}$ & $10^{-3}$ & $10^{-1}$ & $10^{-2}$ & \\
\hline \multirow{3}{*}{1} & 1 & - & - & - & - & - & - & - & - & - \\
\hline & 2 & - & - & - & - & - & - & - & - & - \\
\hline & 3 & - & - & - & - & - & - & - & - & - \\
\hline \multirow{3}{*}{2} & 1 & - & - & - & - & - & - & - & - & - \\
\hline & 2 & - & - & - & - & - & - & - & - & - \\
\hline & 3 & - & - & - & - & - & - & - & - & - \\
\hline \multirow{3}{*}{3} & 1 & - & - & - & - & - & - & - & - & - \\
\hline & 2 & - & - & - & - & - & - & - & - & - \\
\hline & 3 & - & - & - & - & - & - & - & - & - \\
\hline \multirow{3}{*}{4} & 1 & - & - & - & - & - & - & - & - & - \\
\hline & 2 & - & - & - & - & - & - & - & - & - \\
\hline & 3 & - & - & - & - & - & - & - & - & - \\
\hline \multirow{3}{*}{5} & 1 & - & - & - & - & - & - & - & - & - \\
\hline & 2 & - & - & - & - & - & - & - & - & - \\
\hline & 3 & - & - & - & - & - & - & - & - & - \\
\hline
\end{tabular}

* (+) presença de Coliformes na amostra; (-) ausência de Coliformes na amostra.

Os resultados encontrados nos lotes de polpa de cupuaçu do produtor 2 , conforme se nota na tabela 2 , apresentaram-se discrepantes com relação àqueles encontrados na pesquisa com o produtor 1 , pois nas análises realizadas com os 5 lotes de polpa deste produtor, em todos foram observados turvação do meio de cultura e em alguns casos gás no interior do tubo de Durham, indicando que estas amostras precisariam passar por todas as etapas de análise para confirmar o resultados preliminares.

De acordo com Silva et al. (2007), quando ocorre a turvação do meio de cultura utilizado para pesquisas com coliformes, este fato indica que ouve crescimento de microrganismos que são capazes de crescer neste meio de cultura, mas a não produção de gás descarta o crescimento de coliformes na amostra; porém, indica que seria necessário encaminhar estas amostras aos testes subsequentes para a confirmação destes resultados.

Dos 5 lotes coletados no produtor 2, somente 4 apresentaram resultados negativos em todas as etapas de processamento para a detecção de Coliformes, porém apresentaram crescimento de bactérias que são capazes de crescer nos diferentes meios utilizados para realizar análises microbiológicas em alimentos (L.S.T, V. B.B e E.C), e podem apresentar potencial de patogenicidade, pois cresceram a $36^{\circ} \mathrm{C}$.

Porém, a amostra 2 do produtor 2 e somente a triplicata 3 apresentou resultados positivos para o crescimento de coliformes, com turvação do meio de cultura e produção de gás no interior do tubo de Durham. Os resultados encontrados nesta amostra confirmam que a mesma estava contaminada por coliformes totais, porém não apresentou resultados positivos para termotolerantes (houve turvação do meio, mas não houve produção de gás) e para Escherichia coli. 
Tabela 2: Resultado de presença e ausência de Coliformes e termotolerante em amostras de polpa de cupuaçu artesanal comercializadas no Município de Guaraí/TO pelo produtor 2 e que foram inoculadas nos diferentes meios de cultura.

\begin{tabular}{|c|c|c|c|c|c|c|c|c|c|c|}
\hline \multicolumn{11}{|c|}{ PRESENÇA E AUSÊNCIA DE COLIFORMES E TERMOTOLERANTES } \\
\hline & & \multicolumn{3}{|c|}{ L.S.T. } & \multicolumn{3}{|c|}{ V. B.B } & \multicolumn{3}{|c|}{ E.C. } \\
\hline LT & D $T$ & $10^{-1}$ & $10^{-2}$ & $10^{-3}$ & $10^{-1}$ & $10^{-2}$ & $10^{-3}$ & $10^{-1}$ & $10^{-2}$ & $10^{-3}$ \\
\hline \multirow{3}{*}{1} & 1 & - & - & - & - & - & - & - & - & - \\
\hline & 2 & - & - & - & - & - & - & - & - & - \\
\hline & 3 & - & - & - & - & - & - & - & - & - \\
\hline \multirow{3}{*}{2} & 1 & - & - & - & - & - & - & - & - & - \\
\hline & 2 & - & - & - & - & - & - & - & - & - \\
\hline & 3 & + & + & + & + & + & + & - & - & - \\
\hline \multirow{3}{*}{3} & 1 & - & - & - & - & - & - & - & - & - \\
\hline & 2 & - & - & - & - & - & - & - & - & - \\
\hline & 3 & - & - & - & - & - & - & - & - & - \\
\hline \multirow{3}{*}{4} & 1 & - & - & - & - & - & - & - & - & - \\
\hline & 2 & - & - & - & - & - & - & - & - & - \\
\hline & 3 & - & - & - & - & - & - & - & - & - \\
\hline \multirow{3}{*}{5} & 1 & - & - & - & - & - & - & - & - & - \\
\hline & 2 & - & - & - & - & - & - & - & - & - \\
\hline & 3 & - & - & - & - & - & - & - & - & - \\
\hline
\end{tabular}

* (+) presença de coliformes na amostra; (-) ausência de Coliformes na amostra.

A quantidade de contaminação por coliformes totais na triplicata 3 da amostra 2 foi calculada pela tabela do Número Mais Provável, que consta em Silva et al. (2007). Todos os tubos da triplicata 3 apresentaram resultados positivos, como se pode notar na tabela 2 , com turvação do meio de cultura e produção de gás no interior do tubo de Durham. Portanto, a contaminação por Coliformes totais na triplicata 3 da amostra 2 foi de 9,3NMP/g de polpa de cupuaçu. Estes resultados estão acima daqueles preconizados pela RDC $\mathrm{n}^{\circ} 12$ de 02 de Janeiro de 2001, que permite somente 1,0NMP/g de alimento.

Estes resultados estão de acordo com aqueles encontrados nos trabalhos realizado por Lima et al. (2001) que trabalharam com polpas de maracujá e encontraram contaminação nas polpas por Coliformes totais e Termotolerantes. Com estes resultados Lima et al. (2001) afirmam ainda que a contaminação destas polpas foi provavelmente ocasionada devido aos hábitos inapropriados para o processamento das mesmas, ou contaminação cruzada mediada pela inadequada assepsia dos maquinários utilizados para o processamento da matéria-prima. Rodrigues et al. (2017), em seu trabalho intitulado 'Desafios da saúde pública no Brasil: relação entre zoonoses e saneamento', afirmam que a maioria das doenças poderiam ser evitadas caso houvesse uma boa assepsia do ambiente e de utensílios utilizados diariamente para manutenção cotidiana dos indivíduos envolvidos no processo.

Provavelmente, a contaminação desta amostra não é oriunda de falta de higienização no processamento da polpa, caso contrário, todas as triplicatas do lote 2 também teriam apresentado resultados positivos para Coliformes totais. Possivelmente a contaminação desta triplicata pode ter sido mediada por alguma fissura na embalagem do produto que não foi identificada no momento da aquisição da polpa.

Os resultados encontrados nas análises de polpa de cupuaçu do produtor 3 também apresentaram resultados satisfatórios de qualidade microbiológica, pois de acordo com a tabela 3, os 5 lotes analisados 
deste produtor não propuseram resultados positivos para a contaminação por Coliformes, Termotolerantes e Escherichia coli.

Tabela 3: Resultado de presença e ausência de Coliformes e termotolerante em amostras de polpa de cupuaçu artesanal comercializadas no Município de Guaraí/TO pelo produtor 3 e que foram inoculadas nos diferentes meios de cultura.

\begin{tabular}{|c|c|c|c|c|c|c|c|c|c|c|}
\hline \multicolumn{11}{|c|}{ PRESENÇA E AUSÊNCIA DE COLIFORMES E TERMOTOLERANTES } \\
\hline & & \multicolumn{3}{|c|}{ L.S.T. } & \multicolumn{3}{|c|}{ V. B.B } & \multicolumn{3}{|c|}{ E.C. } \\
\hline LT & D & $10^{-1}$ & $10^{-2}$ & $10^{-3}$ & $10^{-1}$ & $10^{-2}$ & $10^{-3}$ & $10^{-1}$ & $10^{-2}$ & $10^{-3}$ \\
\hline \multirow{3}{*}{1} & 1 & - & - & - & - & - & - & - & - & - \\
\hline & 2 & - & - & - & - & - & - & - & - & - \\
\hline & 3 & - & - & - & - & - & - & - & - & - \\
\hline \multirow{3}{*}{2} & 1 & - & - & - & - & - & - & - & - & - \\
\hline & 2 & - & - & - & - & - & - & - & - & - \\
\hline & 3 & - & - & - & - & - & - & - & - & - \\
\hline \multirow{3}{*}{3} & 1 & - & - & - & - & - & - & - & - & - \\
\hline & 2 & - & - & - & - & - & - & - & - & - \\
\hline & 3 & - & - & - & - & - & - & - & - & - \\
\hline \multirow{3}{*}{4} & 1 & - & - & - & - & - & - & - & - & - \\
\hline & 2 & - & - & - & - & - & - & - & - & - \\
\hline & 3 & - & - & - & - & - & - & - & - & - \\
\hline \multirow{3}{*}{5} & 1 & - & - & - & - & - & - & - & - & - \\
\hline & 2 & - & - & - & - & - & - & - & - & - \\
\hline & 3 & - & - & - & - & - & - & - & - & - \\
\hline
\end{tabular}

* (+) presença de Coliformes na amostra; (-) ausência de Coliformes na amostra.

Destarte, o NMP de contaminação dos lotes deste produtor foi de $0,0 \mathrm{NMP} / \mathrm{g}$ de polpa. Porém, os 5 lotes deste produtor apresentaram turvação do meio de cultura, indicando então crescimento de microrganismos que são capazes de consumir estes meios, porém, não são capazes de fermentar lactose produzindo gás no interior do tubo de Durham, porém podem apresentar potencial de patogenicidade, pois crescem a $36^{\circ} \mathrm{C}$.

A ausência de crescimento com turvação e formação de gás nas diluições destes meios testados devese à boa qualidade da matéria-prima aplicada na produção do produto, além do reduzido valor de pH na polpa de cupuaçu que diferencia os resultados destes, quando comparados com os resultados obtidos com a polpa de açaí, além também da possível destruição de microrganismos promovida pelo congelamento (SANTOS et al., 2008; SEBASTIANY et al., 2009). Mesmo o teste presuntivo apresentando resultado negativo estes passaram para as etapas subsequentes com Caldo Verde Brilhante Bile a 2\%, Caldo Escherichia coli e os testes bioquímicos, as quais não fugiram a regra, apontaram respostas negativas, o que Santo et al., (2008) também confirmaram em suas pesquisas.

Diante dos resultados encontrados na presente pesquisa, compreende-se que é suma importância a realização de trabalhos que possam comprovar a qualidade microbiológica de alimentos comercializados no Município de Guaraí, Tocantins, para assim, diminuir os casos de infecção e intoxicação alimentar por entre os moradores do município. 


\section{CONCLUSÃO}

De acordo com os resultados encontrados na presente pesquisa, conclui-se que as polpas de cupuaçu comercializadas no município de Guaraí pelos 3 produtores pesquisados apresentaram ótimos estados de produção, estando a maioria de acordo com o que é preconizado pela legislação para a comercialização de alimentos com estas características, porém, um único produtor apresentou resultados insatisfatório de qualidade microbiológica de um de seus lotes. Acredita-se que esta contaminação não foi ocasionada pelo processamento da polpa ou do embalamento do produto, mas com o transporte e o manuseio nos estabelecimentos de comercialização, que podem ter rompido a embalagem original do alimento e permitido a entrada de contaminação por Coliformes totais.

Desta forma, compreende-se que se faz necessário a realização de ações que possam conscientizar da importância do bom manuseio de alimentos para o consumo humano, assim como, os cuidados necessários de transporte e armazenamento, por meio de palestras educativas e da elaboração de materiais didáticos que informem dos riscos que o consumidor corre ao adquirir e consumir alimentos com embalagens rompidas ou violadas, assim como consumir alimentos de origem duvidosa e com data de fabricação vencida. Também se faz necessário uma fiscalização mais eficaz por parte dos órgãos responsáveis por averiguar as condições de armazenamentos, manuseio e consumo de alimentos comercializados nos estabelecimentos do Município, com o auxílio de estudos específicos e aplicação da punição preconizada pela legislação.

\section{REFERÊNCIAS}

ALVES, N. C.; ODORIZZI, A. C.; GOULART, F. C.. Análise microbiológica de águas minerais e de água potável de abastecimento, Marília, SP. Revista de Saúde Pública, v.36, n.6, p.749-751, 2002.

AMORIM, G. M.; SANTOS, T. C.; PACHECO, C. S. V.; TAVARES, I. M. C.; FRANCO, M.. Avaliação Microbiológica, físico/química e sensorial de polpa de frutas comercializadas em Itapetinga/BA. Enciclopédia Biosfera, v.6, n.11, 2010.

APHA. American Public Health Association. Compendium of methods for the microbiological examination of foods. 4 ed. Olympia: APHA, 2001.

APHA. American Public Health Association. Standard methods for the examination of water and waster water. 20 ed. Olympia: APHA, 1997.

BENEVIDES, S. D.; RAMOS, A. M.; STRINGHETA, P. C.; CASTRO, V. C.. Qualidade da manga e polpa da manga Ubá. Revista Ciência e Tecnologia de Alimentos, v.28, n.3, p.571578, 2008.

BRASIL. Agência Nacional de Vigilância Sanitária. Resolução - RDC n 12. Brasília: DOU, 2001.

BRASIL. Ministério da Agricultura e do Abastecimento.

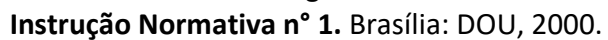

CETESB. Companhia de Tecnologia e Saneamento Ambiental. Relatório de qualidade das águas interiores do estado de São Paulo. São Paulo: CETESB, 2002.

DANTAS, R.; ROCHA, A. P. T.; ARAÚJO, A. S.; RODRIGUES, M. A. S.; MARANHÃO, T. K. L. Qualidade Microbiológica de polpa de frutas comercializadas na cidade de Campina Grande, PB. Revista Brasileira de Produtos Agroindustriais, v.14, n.2, p.125-130, 2012.

FEITOSA, T.; OLIVEIRA, M. E. B.; BASTOS, M. S. R.; MUNIZ, C. R.; OLIVEIRA, S. C. A.. Perfil Microbiológico de polpa de frutas produzidas e comercializadas nos estados do Ceará e Rio Grande do Norte. Boletim do Centro de Pesquisa de Processamento de Alimentos, Curitiba, v.15, n.1, p.65-74, 1997.

FREIRE, M. T. A.; PETRUS, R. R.; FREIRE, C. M. A.; OLIVEIRA, C. A. F.; FELIPE, A. M. P. F.; GATTI, J. B.. Caracterização físicoquímica, microbiológica e sensorial de polpa de cupuaçu congelada (Theobroma grandiflorum Schum). Brazilian Journal Food Technology, v.12, n.1, p.9-16, 2009.

IBGE. Instituto Brasileiro de Geografia e Estatística. Censo demográfico. Rio de Janeiro: IBGE, 2016.

KOEPPEN, W.. Climatologia: Con un estudio de los climas de la tierra. Cidade do México: Fondo de Cultura Economia, 1948. 
LIMA, J. R.; MARTINS, S. C. S.; SILVA, J. L. A.. Avaliação de polpas de frutas congeladas comercializadas no estado do Ceará através de indicadores microbiológicos. Revista Higiene Alimentar, v.15, n.88, p.62-66, 2001.

MARCHI, D. M.; BAGGIO, N.; TEO, C. R. P. A.; BUSATO, M. A.. Ocorrência de surtos de doenças transmitidas por alimentos no município de Chapecó, estado de Santa Catarina, Brasil, no período de 1995 a 2007. Revista Epidemiologia e Serviços de Saúde, Brasília, p.401-407, 2011.

MOREIRA, J. S. A.; SOUZA, M. L.; JOSÉ NETO, S. E.; SILVA, R. F.. Estudo da estabilidade microbiológica e físico-química de polpa de cupuaçu desidratada em estufa. Caatinga, v.24, n.2, p.26-32, 2011.

RAMOS, M. E. C.. Sujidades em polpas de frutas congeladas produzidas em Petrolina/PE e Juazeiro/BA. Recife: Universidade Federal de Pernambuco, 2004.

ROBERTO, M. C.; GUIMARÃES, A. P. M.; RIBEIRO, J. L.; CARVALHO, A. V.; NERES, J. C. I.; CERQUEIRA, F. B.. Avaliação do ph, turbidez e análise microbiológica da água do Córrego Guará Velho em Guaraí, estado do Tocantins. Revista Desafios, v.4, n.4, p.3-14, 2017.

RODRIGUES, C. F. M.; RODRIGUES, V. S.; NERES, J. C. I.; GUIMARÃES, A. P. M.; NERES, L. L. F. G.; CARVALHO, A. V.. Desafios da saúde pública no Brasil: relação entre zoonoses e saneamento. Scire Salutis, v.7, n.1, p.27-37, 2017.
SANTOS, C. A. A.; COELHO, A. F. S.; CARREIRO, S. C. Avaliação Microbiológica de polpa de frutas congeladas. Revista Ciência e Tecnologia de Alimentos, Campinas, v. 28 , n.4, p.913-915, 2008.

SEBASTIANY, E.; REGO, E. R.; VITAL, M. J. S.. Qualidade microbiológica de polpas de frutas congeladas. Revista Instituto Adolfo Lutz, v.68, n.2, 2009.

SILVA, N.; JUNQUEIRA, V. C. A.; SILVEIRA, N. F. A.. Manual de Métodos de Análise Microbiológica de Alimentos. 3 ed. Curitiba: Livraria Varela, 2007.

VANDERZANT, C.; SPLITTSTOESSER, D. F.. Compedium for the microbiological examination of foods. 3 ed. Olympia: American Public Health Association, 1992.

VENTURIERE, G. A; AGUIAR, J. P. L.. Composição do chocolate caseiro de amêndoas de cupuaçu (Theobroma grandiflorum). Revista Acta Amazônica, v.18, n.1, p.38, 1988 .

WELKER, C. A. D.; BOTH, J. M. C.; LONGARAY, S. M.; HAAS, S.; SOEIRO, M. L. T.; RAMOS, R. C.. Análise microbiológica dos alimentos envolvidos em surtos de doenças transmitidas por alimentos (DTA) ocorridos no estado do Rio Grande do Sul, Brasil. Revista Brasileira de Biociências, Porto Alegre, v.8, n.1, p.44-48, 2010. 